\title{
Significaciones y prioridades en la autogestión de las ERT argentinas. EI caso de Chilavert ocho años después de su recuperación
}

\author{
Susana B. DÍAZ RUIZ \\ Universidad de Castilla La Mancha \\ Departamento de Filosofía (Área de Sociología) \\ Susana.diaz@uclm.es
}

Recibido: 25-07-2012

Aceptado: 12-09-2013

\section{RESUMEN}

La recuperación de empresas en Argentina es un proceso protagonizado por algunos trabajadores como respuesta colectiva ante la pérdida de empleo en un contexto nacional marcado por un progresivo empeoramiento de las condiciones laborales que estalla en la crisis del año 2001.

El objetivo de este trabajo, centrado en el protagonismo agencial de los trabajadores, es abordar la significación subjetiva que tuvo para ellos la recuperación. Me serviré para ello de las entrevistas realizadas en Chilavert, una empresa gráfica recuperada de Buenos Aires en el año 2010, ocho después de iniciar el proceso. En éstas se recoge la visión que tienen sobre los acontecimientos, los distintos actores implicados y sobre las acciones llevadas a cabo así como sobre las cuestiones que consideran más importantes sobre la situación actual de la empresa.

Palabras clave: empresas recuperadas por sus trabajadores (ERT), acción colectiva, trabajo, identidad

\section{Meanings and priorities in the self - management of the argentine ert. Chilavert eight years after his recovery}

\begin{abstract}
The recuperation of companies in Argentina is a process played by some workers as a collective response to the loss of employment in a national context characterized by a progressive worsening of working conditions in the 2001 crisis. The objective of this work, focusing on the agential role of workers, is to address the subjective meaning they had for recovery. I shall use for this purpose of the interviews conducted in Chilavert, a recovered company in Buenos Aires in 2010, eight years after starting the process. In these set out the vision they have about the events, the various actors involved and the actions undertaken and the issues they consider important about the current situation of the company.
\end{abstract}

Keywords: enterprises recovery by workers, collective action, work, identity

REFERENCIA NORMALIZADA

Díaz Ruiz, S. B (2014). Significaciones y prioridades en la autogestión de las ERT argentinas. El caso de Chilavert ocho años después de su recuperación. Cuadernos de Relaciones Laborales, Vol. 32, núm. 2, p. 469-490. 
SUMARIO: Introducción y planteamiento contextual. 1. Particularidades de las ERT en Argentina. 2. La visión de los acontecimientos. 3. La visión de lo más importante. 4. La visión de las debilidades y fortalezas. 5. La visión de futuro. 6. Conclusiones. 7. Bibliografía.

\section{Introducción y planteamiento contextual ${ }^{1}$}

El fenómeno de las ERT (Empresas Recuperadas por sus Trabajadores) en Argentina captaba la atención de los medios de comunicación como una consecuencia de la crisis del 2001. En medio de una situación social de paro y pobreza desconocida hasta ese momento en el país, algunos trabajadores recuperaban sus empresas en situación de ruina para volver a ponerlas en funcionamiento bajo autogestión colectiva.

Sin embargo, el estallido de esta crisis no marcaba el comienzo del paro y la pobreza en Argentina ni tampoco representaba el origen de las ERT. La década de los 90 se abre con un $33,7 \%$ de personas por debajo del umbral de la pobreza y una tasa de desocupación del 6,7\%. En 1996 estos porcentajes alcanzaron el 26,7\% y el $18 \%$, respectivamente, y en el año 2000 un $29,7 \%$ y un $16 \%$. En el año 2002 la población en situación de pobreza se cifra en un porcentaje superior al $54 \%$ y casi un $19 \%$ de la población está desocupada (INDEC, 2002) ${ }^{2}$.

Estos datos se enmarcan dentro de la persistencia y agravamiento mundial de la pobreza, desempleo, precarización laboral, desigualdad y explotación que ha concitado el consenso de numerosos autores alrededor de un análisis que señala el déficit democrático del actual modelo de globalización como razón principal de la determinación que sufre la política por parte de la economía y la consiguiente primacía que adquieren así los intereses particulares sobre los generales (Stiglitz, 2006).

Es en este marco en el que el paradigma de producción flexible, sobreorientado a una rentabilidad cortoplacista, se ha hecho dominante generando efectos de precariedad e incertidumbre en las condiciones de trabajo y vida que han ido afectando a cada vez más sectores de la población mundial (Sennett, 2000; Alonso, 2000; Carnoy, 2001; Prieto, 2002; Castillo, 2003; Castells, 2005).

\footnotetext{
${ }^{1}$ Este trabajo se realizó a través de una estancia académica realizada en la Facultad de Ciencias Sociales de la Universidad de Buenos Aires (UBA) con el profesor Juan Silva y ha contado con la ayuda y revisión de Andrés Ruggeri, profesor de Antropología Social de la UBA y director del Programa Facultad Abierta y Natalia Polti, antropóloga (UBA) y coordinadora del Centro de Documentación de Empresas Recuperadas (Programa Facultad Abierta).

2 "Evolución de la indigencia, la pobreza y la desocupación en el GBA desde 1988 en adelante”. INDEC (Instituto Nacional Estadística y Censos Argentina) 2002.
} 
Sin embargo, a pesar del grave cuestionamiento que sufre la sostenibilidad del modelo global dominante, también existe, como advierte de Soussa, un "gran desperdicio de experiencias" (De Soussa, 2006: 18), respuestas de lucha y resistencia protagonizadas por la gente para defender sus derechos y condiciones de vida. La recuperación de empresas como respuesta de autorganización colectiva en la que se revierte la situación dramática de perder el trabajo en medio de una crisis nacional que hace descartables las opciones de encontrar otro o de sobrevivir con las ayudas asistenciales, son una de esas experiencias.

El objetivo de este artículo es abordar la significación subjetiva que tiene el proceso de recuperación en la discursividad narrativa de los trabajadores de la gráfica Chilavert ocho años después de que decidieran iniciarlo ${ }^{3}$. Se utilizó una metodología cualitativa que consistió en la realización de seis entrevistas semi estructuradas con los trabajadores de esta empresa orientadas a conocer su percepción sobre la recuperación emprendida a partir de la identificación que hacen de las cuestiones más importantes del proceso así como de las potencialidades y dificultades que hoy enfrentan ${ }^{4}$. También se consultaron fuentes estadísticas y bibliográficas especializadas en las empresas recuperadas.

Se intentó realizar un taller participativo que finalmente no encontró respuesta en los trabajadores de Chilavert, un tanto decepcionados por anteriores propuestas similares en las que los resultados no fueron los esperados. Sin embargo, los presupuestos fundamentales de la I-A-P propuestos por Greenwood han estado presentes durante el mes y medio que duró el trabajo de campo. En primer lugar, en cuanto a la consideración de los actores como "dueños de la problemática" (Greenwood, 2000:32) y en segundo, en cuanto al establecimiento de relaciones horizontales y colaborativas (Greenwood, 2000:47) con los trabajadores y con el personal del Centro de Documentación de ERT ubicado dentro del taller de Chilavert $^{5}$, así como con voluntarios que colaboran con diversas actividades sociales como el Bachillerato de secundaria o el centro cultural "Chilavert recupera", cuya consistencia desarrollaré más adelante.

${ }^{3}$ La recuperación de se inicia en el año 2002, concretamente la fecha que celebran los trabajadores es el 17 de octubre porque ese día reciben las llaves de la cooperativa tras fallarse a su favor en la legislatura la tenencia temporaria por dos años y continúan trabajando ya de manera legal. Son ocho los años transcurridos desde que se hacen las entrevistas en el año 2010.

${ }^{4}$ Ante las diferentes maneras en las que los trabajadores preferían aparecer identificados en el trabajo se optó por utilizar "trabajador de Chilavert".

${ }^{5}$ El Centro de Documentación está integrado por el equipo de investigación del Programa Facultad Abierta de la Facultad de Filosofía y Letras de la UBA, Desde ahí se facilitó toda la información sobre bibliografía e investigación de ERT además de la orientación necesaria para centrar las preguntas de las entrevistas perfilando el objetivo y planteamiento inicial. 


\section{Particularidades de las ERT en Argentina}

El término Empresas Recuperadas por sus Trabajadores (ERT) es el término utilizado por los trabajadores para denominar a aquellas empresas que desde una situación de quiebra o abandono por parte del empresario fueron de nuevo puestas en funcionamiento por ellos. Este es el motivo de su uso en la investigación social, "ser llamadas por sus protagonistas empresas recuperadas" (Ruggeri, 2009: 13). Lo hicieron con sus propios recursos pues no existía ninguna legislación específica, no se contaba con el apoyo de los sindicatos y las prácticas judiciales se caracterizaban por la discrecionalidad (Ruggeri, 2009: 45).

Una primera caracterización de las ERT en Argentina, según señalan diversos autores, las define como empresas en situación de quiebra y abandono que en la mayoría de los casos se vieron precedidos por saqueos ilegales de bienes por parte del empresario (Magnani, 2003; Rebón, 2004, Ruggeri, Martínez y Trinchero, 2005). Y aunque relacionadas con la crisis del 2001 , la existencia de un $14,6 \%$ de recuperaciones que se producen con anterioridad nos ofrece una contextualización que trasciende el marco inmediato que ésta representa y nos sitúa ante la continuada lucha que protagonizan históricamente los trabajadores concretando así su significado como respuesta colectiva defensiva del puesto y las condiciones de trabajo (PFA, 2003, 2010). En la mayoría de estos casos el traspaso de la gestión privada a la gestión cooperativa de los trabajadores se llevó a cabo mediante acuerdos y además no se trataba de empresas ruinosas (Ruggeri, 2009).

La situación, sin embargo, en 2001 es muy diferente y aunque no puede reducirse el papel de la crisis a un factor determinista, sí puede hablarse de su influencia y de las diferencias que presentan las empresas que son recuperadas en esos momentos. Diferencias fundamentalmente relacionadas con el clima de conflictividad y movilización social que se vive en el país (Magnani, 2003) y con el carácter "inédito" que presentan las recuperaciones iniciadas con la ocupación y la autogestión (Ruggeri, 2004).

Dado el cuestionamiento social que se hace sobre responsables políticos e institucionales no se trata de una crisis económica sino también política. Entre los días 19 y 20 de diciembre de 2001 es declarado el estado de sitio y se producen cuarenta muertos y cientos de heridos en enfrentamientos con la policía. Al día siguiente el presidente De la Rúa dimite y tiene que salir en helicóptero de la Casa Rosada.

La pérdida de legitimidad de políticos y empresarios en el aumento de recuperaciones que se producen en estos momentos resulta clave a juicio de Julián Rebón:

Por una parte, constituyó un clima de desobediencia e inconformidad que nutrió la posibilidad de desobedecer la decisión capitalista de abandonar la producción. Por otra, creó sensibilidad social para que las recuperaciones se difundieran (Rebón, 2006:155). 
Los cierres de empresas se suceden y encontrar otro trabajo deja de ser una posibilidad en estos momentos con más de la mitad de la población desempleada. El desempleo, ahora permanente, define una situación de necesidad sin opciones (Perelman, 2002). Junto a las deudas salariales, los despidos y la precarización que se vienen viviendo, la quiebra y el vaciamiento fraudulento como práctica empresarial habitual son las principales razones de los trabajadores que impulsan su decisión conjunta de iniciar la recuperación (PFA, 2010). La consideración que hacen de la situación que están viviendo como de inaceptable adquiere una importancia destacada en la toma de esta decisión (Fernández Alvárez, 2004; Ruggeri, Martínez y Trinchero, 2005; Rebón, 2006). A pesar de que algunas de las recuperaciones que tienen lugar en la crisis se llevan a cabo mediante el acuerdo entre los trabajadores y los antiguos dueños (Ruggeri, 2009: 43), en el 62\% de las ERT los trabajadores usaron diferentes tipos de medidas de fuerza como tomas, acampadas y movilizaciones (PFA, 2010).

En este marco la significación de las tomas en el proceso de recuperación adquiere precisión y se aleja de la centralidad que se les ha otorgado en algunas presentaciones del fenómeno como el documental "La Toma", dirigido en 2004 por Naomi Klein y Avi Lewis y, en general, de visiones idealizadas en las que se erige en prueba simbólica del augurado triunfo de la clase trabajadora. Su realidad concreta como respuesta colectiva de los trabajadores, generada en una situación de necesidad y falta de alternativas, es bien distinta. Las tomas no fueron sino el primer paso del largo e incierto proceso de recuperación que ahí comienza y cuyo objetivo final es el de volver a poner en funcionamiento la empresa (PFA, 2003; Rebón, 2004).

Los trabajadores asisten a un transcurso regular de los acontecimientos en el que tras el abandono de la empresa, el empresario deja tras de sí las deudas contraídas con los trabajadores y proveedores y solicita la quiebra. A partir de ahí las posibilidades se concretan para ellos. O asisten al proceso de quiebra recogido en la Ley de Concursos y Quiebras que significa para los trabajadores asistir a la pérdida del trabajo, al vaciamiento fraudulento de los bienes empresariales por parte del empresario con la complicidad de jueces y representantes sindicales y olvidarse de la posibilidad de cobrar los salarios adeudados 6 , o tratan de evitar el cierre.

En esta situación tratar de recuperar la empresa se percibe como una posibilidad frente a la exclusión social (Trinchero, 2007). Y para ello hay que empezar por evitar que los bienes de la empresa sean extraídos, bien de manera ilegal por parte

${ }^{6}$ Como explica Ruggeri la aplicación de los pagos a los acreedores que establece la ley privilegia en el cobro a los bancos dejando fuera del cobro de las deudas a los trabajadores, Ruggeri, 2009) 
del empresario, bien por el dictamen judicial para efectuar el concurso de acreedores ${ }^{7}$.

A la situación de extrema necesidad que viven los trabajadores se añade la percepción de profunda injusticia y los sentimientos de completa desprotección institucional que, sin embargo, cuentan con los apoyos sociales recibidos y la legitimidad social que atribuyeron a su respuesta colectiva. Una respuesta que inevitablemente exigió a los trabajadores enfrentar las consecuencias de las acciones ilegales iniciadas que hasta en un $50 \%$ de los casos fueron represaliadas por las fuerzas policiales (PFA, 2010).

Legitimidad y legalidad se distancian, emergiendo la acción directa como mecanismo de resolución de la tensión. Esta brota como gesto de desobediencia práctica, como resistencia frente a la muerte social anunciada de su identidad. (Rebón, 2006: 162)

La promulgación en 2002 de las Leyes de Expropiación Temporaria explica que las ERT adopten la forma de cooperativas autogestionadas. Esta ley declara el carácter de utilidad pública de la empresa y tras la expropiación el Estado paga al juez quien se encarga de pagar a los acreedores. La empresa pasa a ser así propiedad estatal y durante dos años, con opción a renovación, la empresa es cedida a la cooperativa de trabajadores. A partir de la existencia de esta ley las acciones de los trabajadores van encaminadas a tramitar la solicitud de la expropiación para continuar trabajando y a paralizar el proceso de quiebra y el remate de los bienes empresariales. Por eso las tomas son la acción con la que tratan de defender la empresa como fuente de trabajo y reivindicar el pago de sus deudas. El objetivo final no es otro que el de seguir trabajando y ahí es donde se explicita el significado que adquiere la recuperación como proceso.

Resistir, entonces, como explica Ruggeri, significa "soportar las presiones a que se ven sometidos para poder sostener su vida en términos materiales y su dignidad como trabajadores". (Ruggeri, 2009: 45). El sentido político de la lucha de los trabajadores alcanza aquí su máxima expresión porque es la recuperación el objetivo y fin que se persigue y de donde se desprende el carácter autogestionario de la recuperación que ha significado la sostenibilidad del empleo para sus trabajadores ${ }^{8}$. Son los trabajadores quienes recuperan y quienes gestionan, sin ser

${ }^{7} \mathrm{Y}$ aunque en el año 1995 se aprueba una modificación de la ley que en casos extraordinarios establece que el juez puede dar la tenencia precaria de la empresa a los trabajadores, la única opción que éstos tienen tras la resolución de la quiebra es comprar la fábrica en el remate de bienes.

${ }^{8}$ Paralelamente, organismos oficiales como el BID (Banco Interamericano de Desarrollo) han mostrado su rechazo al uso de la palabra recuperadas. Según recoge en su libro el equipo de investigación Programa Facultad Abierta en una reunión mantenida con una representante del BID, ésta rechazó el uso de esta palabra poniendo de manifiesto "la 
por ello la autogestión un término relevante en la consideración identitaria que tienen de sí mismos, expresada discursivamente en la palabra "trabajadores" (Ruggeri, 2009: 28).

A través de datos recogidos en el Tercer Relevamiento sobre ERT en Argentina se puede visualizar una panorámica a nivel nacional. El número de ERT en Argentina en el año 2010 se cifran en 205 ERT y representan 9632 puestos de trabajo, lo que significa un aumento de 44 y 2462, respectivamente, en relación al año 2004. La mayor parte de ellas, un total de 76 , se encuentran localizadas en el Gran Buenos Aires aunque cabe destacar la existencia de ERT en provincias como Santa $\mathrm{Fe}$ donde hay veinte, Mendoza siete o Córdoba y Entre Ríos donde se localizan cinco (PFA, 2010).

Por su tamaño, el $75 \%$ son Pymes que cuentan con menos de 50 trabajadores. Y en cuanto a los sectores productivos en los que se ubican el más numeroso, con un $23,41 \%$, es el de las empresas metalúrgicas, seguido de las alimenticias con un $12,68 \%$, gráficas con un 7,8\%, textiles e industrias cárnicas un $6,34 \%$, construcción con un $5,85 \%$, salud un $4,88 \%$, o transporte con un $2,93 \%$, entre otras. Y a pesar del estado de quiebra en el que se encontraban cuando fueron recuperadas, un $60 \%$ han incorporado maquinaria con la inversión de los trabajadores (PFA, 2010).

Aunque el proceso de recuperación de empresas es altamente heterogéneo dadas las diferencias y matices que en cada uno de los casos se derivan de su concreción real, todos los elementos hasta aquí mencionados pueden considerarse característicos de las ERT en Argentina. A pesar de su escasa significación cuantitativa su relevancia reside en su consistencia más básica: algunos trabajadores, con sus propios recursos y los apoyos que generaron en la sociedad argentina, volvieron a poner en funcionamiento empresas quebradas, al borde del cierre después de varios años de completa incertidumbre e incumplimientos del contrato, protagonizaron una respuesta colectiva que posibilitó que no perdieran su trabajo.

A través de los discursos de los trabajadores de Chilavert abordo en este epígrafe la significación que la recuperación iniciada en el año 2002 ha tenido para sus protagonistas y las cuestiones más importantes que destacan tras el tiempo transcurrido.

\section{La visión de los acontecimientos}

Las condiciones laborales desde finales de los noventa se habían deteriorado en la antigua Gaglione de manera continuada sucediéndose suspensiones de la producción, impago de horas extras y deudas salariales. Ya desde 1998 los trabajadores identifican las dificultades económicas por las que venía atravesando la empresa. Con el estallido de la crisis en el año 2001 la incertidumbre de muchos

alusión al atentado a la propiedad empresaria y al fracaso capitalista que representa la empresa recuperada" (Ruggeri, 2009: 30). 
trabajadores ante los cierres sucesivos es generalizada y el caso de Chilavert no es una excepción.

“el dueño hizo una reunión y nos dijo que iba a comprar una máquina nueva, que no nos iba a pagar las horas extras y seguimos trabajando doce horas, sábados, a veces domingo, y no nos pagaba todo, por ejemplo, pagaba una parte, y todo lo que yo no les voy dando, nos decía, lo vamos poniendo en la cuenta y lo vamos anotando; yo lo único que le dije es mire el sueldo no me lo ponga en negro porque yo estoy a punto de jubilarme, en ese año que estuvimos trabajando así a mí me agarró un infarto, claro, de los mismos nervios, había mucha desconfianza" (trabajador de Chilavert)

A pesar de la incertidumbre y la angustia los trabajadores iban a trabajar cada día sin saber muy bien con qué se iban a encontrar. El momento que marca un antes y un después es cuando los trabajadores averiguan que el empresario trata de engañarles a pesar de decirles que todo se iba a arreglar sustituyendo algunas máquinas viejas por otras nuevas. Gracias a la ayuda de una abogada, familiar de uno de los trabajadores, comprueban que el empresario ha solicitado la quiebra y que las máquinas que dice va a sustituir por otras nuevas han sido ya inventariadas para el concurso de acreedores.

Descubrir primero y comprobar después que la verdadera intención del empresario era sacar algún dinero vendiendo esas máquinas les sitúa en una posición distinta. Hasta ese momento su narración confiaban en el dueño ya que en otras ocasiones difíciles como esta le habían ayudado a salvar la situación aceptando cambios en las condiciones laborales como disminuciones de salarios e impago de horas extras. Pero esta vez no era una situación puntual, sino definitiva.
"nosotros confiábamos siempre en el patrón porque no es que de un día para otro dijéramos, bueno vamos a tomar esto, no... nosotros estuvimos dos años colaborando con la empresa, hasta llegó un punto de que nos llegaron a pagar el colectivo, tres, cuatro pesos por semana, no es que un día nosotros nos levantamos y decimos... vamos a tomar la empresa, no, esto no, tuvimos una deuda tan grande, ja mí me quedó una deuda de 30. 000 pesos!" (trabajador de Chilavert)

Las opciones reales que enfrentan a partir de este momento se concretan. O se marchan, pierden el empleo y los salarios adeudados en un momento donde los subsidios estatales de desempleo eran del todo insuficientes para mantener a sus familias y las posibilidades de encontrar trabajo impensables, o tratan de evitar el cierre.

“entonces ahí fue ese el quiebro, o aceptamos nuevamente que nos pase lo que ya nos pasó o esta vez enfrentamos, ... el dueño me dijo yo quisiera hacer algo por ustedes pero no puedo, entonces, lo que me da es que tengo que cerrar, digo, bueno, usted cierre, ya nos empezó a hacer más la guerra, de que iba a cerrar, iba a cerrar, fueron tiempos muy duros, él estaba decidió a cerrar, ...porque nosotros no 
queríamos perder la fuente de trabajo, y qué hacemos, qué hacemos porque no hay otra solución de la patronal y menos de parte del estado, el ministerio de trabajo que es el que nos tiene que defender no hizo nada como para obligar a los dueños a que digan bueno qué estaba pasando, obligarlos a pagarnos los salarios, entonces estábamos como desamparados, no teníamos..., claro, el que te tiene que defender no te defiende, entonces yo conocía a la gente de Impa" (trabajador de Chilavert)

En la conformación de esta alternativa destacan fundamentalmente dos cuestiones. En primer lugar, saber que alguien en el que habían confiado hasta ese momento y al que habían apoyado en ocasiones anteriores está tratando de engañarles cambia radicalmente la percepción que tienen del empresario y les da razones justificadas para plantearse actuar. La consideración que hacen los trabajadores sobre una nefasta gestión y un mal comportamiento empresarial en un contexto de crisis como el que se vivía en esos momentos agrava, no sólo la percepción de completa indefensión, sino de profunda injusticia.

En segundo lugar, la pérdida de legitimidad que sufren políticos y empresarios tiene una notable influencia en la percepción de los trabajadores sobre la posibilidad de subvertir esa situación a la que se añaden los casos de recuperaciones que ya se han dado y que serán para los trabajadores de Chilavert referencias concretas y reales de actuación.
"bueno, en realidad, como lo entiendo yo, lo que nosotros hicimos no fue tanto por un convencimiento y por llevar a cabo un objetivo, sino empujados por la situación de quiebra y necesidad, eso fue fortaleciendo una serie de valores que uno tiene, no?" (trabajador de Chilavert)

Tras los contactos y asesoramiento jurídico que les proporcionan IMPA, una metalúrgica recuperada, comienzan a conocer qué pasos había que empezar a dar en caso de iniciar la recuperación. Sólo entonces se produce el comienzo de la acción colectiva por parte de ocho trabajadores que deciden iniciar el proceso 9 .

Aunque se trataba de una situación muy difícil cuyo desenlace final desconocían y hubo situaciones conflictivas en otras empresas, en el caso de Chilavert, los discursos recogidos destacan de manera significativa, y no sin humor, la ausencia de conflictividad en los primeros momentos de la toma. Los trabajadores cuentan cómo al comienzo del encierro el dueño de la empresa, con tono paternalista, les animaba a que no perdieran el tiempo permaneciendo allí y a que se convencieran de que aquello no daba más.

"Luego ya el patrón nos venía a visitar y nosotros no lo dejábamos entrar, cuando él pidió la quiebra, le pusimos la camioneta delante y cada vez que

\footnotetext{
${ }^{9}$ En ese momento Gaglione contaba con treinta trabajadores.
} 
tocaba nos mirábamos y nos encogíamos de hombros, ya no lo dejábamos entrar, la primera vez que vino le dijimos maestro qué viene a hacer acá si usted ya pidió la quiebra, ya la imprenta no es suya, así no venga más, y decía ah, yo vengo a buscar cosas, no usted tuvo tiempo de llevarse sus cosas, no se las llevó, ahora quedan adentro, ya para la convocatoria, si no qué vamos a cobrar nosotros, bueno, entonces el tipo quedó tranquilo, venía a ver si le dábamos algo, nada, ..." (trabajador de Chilavert)

Sin embargo cuando el empresario comprueba que los trabajadores no van a abandonar el taller ni a permitir que saquen las máquinas la manera de dirigirse a ellos cambia y el ultimátum se hace explícito. Uno de los trabajadores recuerda estas palabras: "Miren, yo quisiera hacer algo por ustedes pero no puedo, son ustedes o yo...". A partir de entonces también se explicita la lucha de los trabajadores en el carácter defensivo que adopta. Es una lucha "por" su propia supervivencia y dignidad en la medida que sienten estar en una situación de máxima urgencia y profundamente injusta.

“... si a nosotros nos hubieran pagado, es una cosa normal, a vos te paga, te vas, bueno desde ahí para allá, pero irte así sin nada después de que nosotros en el 97 tuvo una cosa parecida, le pusimos el hombro igual y salimos adelante, luego ya en el 2001 cuando vinieron todos los problemas también, pusimos el hombro, nos bajaron las horas, cobrábamos las horas extras en negro, a veces no las cobrábamos y bueno hasta cuando llegamos a ese límite de llevarnos dos o tres pesos para el colectivo para viajar, yo tuve la suerte de que me ayudó mucho mi señora, mi hermana, pero vivíamos acá adentro, yo no tenía tres o cuatro años acá adentro, yo tenía 18 años y soy uno de los que menos tenía, hay quien tenía 40, 50 años de trabajo, a aparte que nosotros no éramos personas conflictivas, no, si había que venir a trabajar, hemos venido, hemos trabajado de noche" (trabajador de Chilavert)

La lucha que se inicia con el encierro y la toma del taller no es sino el comienzo de la resistencia en la que la recuperación es el objetivo que da sentido a la acción colectiva emprendida y no la toma en sí. La precisión que alcanza la lucha de los trabajadores por no perder el puesto de trabajo se enmarca en enfrentar, por un lado, una situación generalizada de abusos, incumplimientos y prácticas fraudulentas empresariales y por una constante precarización de las condiciones laborales. Por otro lado, y no menos importante, su lucha representa también un rechazo a las alternativas estatales de subsidiariedad, expresando así no sólo su insuficiencia, sino la concepción implícita que en éstas se reserva para ellos como sujetos pasivos y contabilizados estadísticamente bajo la categoría de excluidos sociales.

“en el 2001, 2002, vos sabías que te ibas de acá y que eras una persona desocupada y que no salías para nada por la edad, con 42 años en el 2002 no te daba trabajo nadie, eras un inútil para la sociedad" (trabajador de Chilavert) 
"en la empresa privada no te llaman por la edad, tú sabes la de entrevistas que tuve en cuatro años, muchísimas, terrible, y te desesperás, me tomaba el colectivo, haciéndome mala sangre, cagarme de frío, y llegabas a casa, y tu mujer te pregunta ¿conseguiste?, no, pasé toda esa etapa mal, pelearte con tu mujer, va todo mal, todo en cadena va, cuando trabajás sos un fenómeno pero y cuando no trabajás sos un vago, sos un ..." (trabajador de Chilavert)

"una persona con cuarenta y pico de años como nosotros, o estamos acá adentro o vamos a juntar cartón en la calle, porque otra cosa no podemos hacer, no trabajaban los pibes más jóvenes, imagínate" (trabajador de Chilavert)

“justo veintiún años cumplía yo en la empresa y cuando piensas que ya estaba tu vida más o menos planeada y estabilizada, te cae eso no?, te caes en un pozo negro que encima no tiene fondo, yo lo que le dije al dueño fue nos cortaste las manos" (trabajador de Chilavert)

Lejos, por tanto, de representar ofensivas contra el patrón planeadas desde idearios revolucionarios doctrinarios, las experiencias de las ERT son una respuesta colectiva para defender el trabajo, para evitar perderlo. Es, en definitiva, una lucha por mantener el trabajo, expresada a lo largo de los momentos clave que se distinguen en el proceso de recuperación y que han sido el lema del MNER "Ocupar, resistir, producir" 10 .

"fueron tiempos muy duros, él estaba decidido a cerrar, entonces el desafío se hizo más grande, porque nosotros no queríamos perder la fuente de trabajo, y qué hacemos, porque no hay otra solución de la patronal y menos de parte del estado, el ministerio de trabajo que es el que nos tiene que defender no hizo nada como para obligar a los dueños a que digan bueno, qué está pasando, obligarlos a pagarnos los salarios, entonces estábamos como desamparados, si el que te tiene que defender no te defiende ¿qué haces?, entonces no es que nosotros les corrimos a los patrones, o les echamos, ¿quién echa a quién?” (trabajador de Chilavert)

"yo lo que les dije a los chicos es mirá, ya estamos jugados, vamos a fijarnos a ver si hay chapa porque arriba había muchas chapas de aluminio, las chapas de aluminio

${ }^{10}$ En el año 2001 surge el Movimiento Nacional de Empresas Recuperadas (MNER) alrededor de veinte ERT que comienzan a organizarse para apoyar a otros emprendimientos que iniciaban el proceso de la recuperación. En un momento de gran movilización en el país en el que la gente organiza asambleas en los barrios y se crean clubes de trueque, hay una diferencia fundamental entre estas organizaciones y las ERT: la puesta en práctica de una acción directa encaminada a impedir el cierre de la empresa. Desde entonces han aumentado el número de organizaciones de ERT como MNFRT, Red Gráfica, FACTA o FECOOTRA, entre otras (Ruggeri, 2009). 
se venden, entonces hay que buscar quien la venga a buscar y hacemos un fondo hasta que podamos resistir" (trabajador de Chilavert)

La ocupación del taller se ve acompañada de acciones en otros frentes. A partir de ese momento, mientras iniciaban las diligencias administrativas para registrarse como cooperativa y acogerse a la Ley de Expropiación Temporaria, establecieron como objetivos prioritarios resistir el encierro y el desalojo policial que tarde o temprano esperaban que se produjera. Durante los ocho meses que permanecieron dentro del taller establecieron turnos para garantizar la integridad del inmueble, para hacer la comida y para buscar medios con los que poder iniciar la producción.

A pesar de tratarse de una situación que califican de muy dura, los discursos sobre el desalojo policial con el tiempo han pasado a relacionarse en la memoria de los trabajadores con recuerdos y anécdotas que giran en torno al desproporcionado despliegue de medios.

“cuando viene la policía, y que no pudieron hacer nada, estábamos acá encerrados, y estábamos trabajando, ahí es donde sacamos el libro de las asambleas populares, y después date cuenta de la mentalidad, qué pensaron la policía para poner ocho patrulleros y éramos ocho acá adentro... (risas)" (trabajador de Chilavert)

Frente a cientos de vecinos que se interponen ante la puerta del taller finalmente el juez levanta la orden de desalojo y durante seis meses un vigilante permaneció en la puerta del taller para impedir que sacaran cualquier cosa del interior. Los trabajadores de Chilavert, y esta es una de las anécdotas de mayor simbolismo en la historia de la recuperación de la empresa, cuentan con la ayuda del vecino de la casa contigua al taller a quien se le ocurre hacer un agujero en la pared para poder sacar así los volúmenes que ya estaban imprimiendo. Curiosamente era un libro que llevaba por título "Las asambleas populares". Ese agujero está hoy enmarcado en el taller.

Los apoyos fueron de gran importancia para los trabajadores. La ayuda de vecinos, familiares y asociaciones resultó crucial para resistir a los intentos policiales de desalojo así como la ayuda recibida por parte de otros trabajadores de empresas recuperadas como en este caso IMPA, de quienes reciben el asesoramiento para solicitar la expropiación. Y más allá del carácter material y logístico que aportan estas ayudas, la significación fundamental que tuvieron es la legitimidad que se deriva de éstas y que otorgan a su acción frente a la actuación engañosa e intencionalmente fraudulenta del empresario.

Dicha legitimidad se presenta discursivamente enmarcada de pleno en el contexto que estaba viviendo el país en ese año, caracterizado por las movilizaciones y protestas sociales que explicitaban una visión compartida sobre las causas y los actores responsables de la situación por la que estaban atravesando miles de trabajadores en todo el país. En palabras de Rebón, "las fábricas y empresas recuperadas eran vividas, por muchos, como la necesidad de recuperar un país que ya no existía” (Rebón, 2006: 170). 
En ese sentido, la identificación que hacen de los distintos actores que les apoyaron expresa la legitimidad social con la que contaron frente a la simultánea pérdida de legitimidad y credibilidad de la clase política y empresarial argentinas.

\begin{abstract}
"ellos consideraban que era una injusticia y que había que hacer algo, era una situación particular, era el verano del 2002, hubo toda una situación incluso de poco respeto a la autoridad, del gobierno, lo que sea, no?, muchas cuestiones, se entendía como algo legítimo, decidieron adaptarse a la situación real y se consiguió una gran conciencia que habiendo tanta desocupación y tanto drama humano cerrar fuentes de trabajo, había que lograr una solución y a partir de ahí hubo mucha gente que se comprometía, no?, nos ayudaban" (trabajador de Chilavert)
\end{abstract}

En 2004 se promulga una ley de expropiación definitiva que afecta a trece ERT de la ciudad de Buenos Aires entre las que se encuentra Chilavert. Esta ley establece la venta a la cooperativa tras la expropiación de la empresa concediendo un plazo de gracia de tres años para pagar y veinte cuotas anuales con las que el estado pagará a los acreedores. Aunque después de ocho años de su promulgación el Estado no ha realizado aún los pagos a los acreedores y existe la posibilidad de que dicha ley caduque en menos de un año si no se efectúan gracias al reciente veto del gobierno de Buenos Aires de una prórroga de la ley.

Los datos del Tercer Relevamiento permiten contrastar la concreción de las ayudas y la situación legal en la que se encuentran en el país las ERT. El 85\% de las empresas han recibido subsidios por parte del Estado, un $32 \%$ dice haber recibido apoyo político por parte de autoridades municipales o provinciales, un $19 \%$ recibieron la ayuda en forma de actividades de capacitación, un $18 \%$ asesoramiento legal y un $14 \%$ planes sociales (PFA, 2010).

Frente a estos apoyos, un $63 \%$ de las ERT fueron expropiadas, temporaria o definitivamente, a favor de la cooperativa; un $8 \%$ se encuentran actualmente tramitando la expropiación, el mismo porcentaje fueron alquiladas por los trabajadores a los antiguos dueños; un 5\% cuyos trabajadores continúan aún hoy ocupando la empresa ante la falta de resolución legal y un $2 \%$ fueron compradas por los trabajadores en el remate de bienes (PFA, 2010).

Estos resultados no permiten hablar de una implicación institucional real en la defensa de los trabajadores sino más bien constatar la falta de voluntad y responsabilidad política en la resolución de la situación. En este sentido Rebón califica de ambigua la actuación del gobierno, "más allá de algunos gestos positivos, sea por desidia o por falta de convicción, la recuperación no se ha configurado como política de Estado." (Rebón, 2006: 169). Por su parte Ruggeri afirma que "el interés de legisladores y gobernantes ha sido antes que nada sacarse de encima la presión de trabajadores, movimientos sociales y opinión púbica en momentos de extrema debilidad institucional y política." (Ruggeri, 2009: 46). 


\section{La visión de lo más importante}

Dos son las cuestiones en torno a las cuales se articulan las consideraciones de los trabajadores sobre lo más importante de la recuperación. La coincidencia de respuestas se produce al señalar, en primer lugar, la conservación del trabajo como lo más importante y estrechamente ligada a ésta, en segundo, la capacidad para defenderlo, sinónimo de la lucha por un trabajo y unas condiciones de vida dignas.

"para mí lo más importante es mantener la fuente de trabajo" (trabajador de Chilavert)

"no perder el trabajo, la lucha por no perderlo, eso es lo más importante" (trabajador de Chilavert)

El mantenimiento del trabajo se hace sinónimo de defenderlo en una situación forzada por la necesidad extrema de los trabajadores y por la indefensión. Dicho objetivo aparece discursivamente sostenido en diversos pilares. En primer lugar, cabe destacar el carácter colectivo del protagonismo agencial desde el que emprenden la defensa del trabajo así como la autonomía y capacidad de autorganización como medios principales. En segundo lugar, su identidad como trabajadores, estrechamente ligada a la dignidad de sus condiciones de trabajo y de vida.

"para mí lo más importante que la experiencia, más allá de la cosas positivas y negativas que puedan darse, lo más importante es todo lo que aprendimos, y las habilidades que descubrimos de nosotros, que de otra manera probablemente no se hubieran desarrollado en otra situación, la capacidad digo, no?, de organización, de toma de decisiones y esas habilidades que uno va desarrollando con la necesidad de responder al trabajo cotidiano que en la vieja forma de trabajar no tenían en este lugar, como cualquier lugar en este mundo, donde hay uno que manda y otro que obedece" (trabajador de Chilavert)

\section{La visión de las debilidades y de las fortalezas}

En las entrevistas se incluyeron preguntas sobre las cuestiones que representaban para los trabajadores de Chilavert los principales obstáculos o dificultades y aquellas que, por el contrario, eran las mayores fortalezas o potencialidades. Las debilidades se localizan discursivamente alrededor de dos cuestiones. La primera de ellas es la dificultad económica para acometer la compra de nueva maquinaria que consideran necesaria. A pesar de que ya compraron algunas máquinas, una renovación más completa de éstas sigue siendo una cuestión importante.

"el déficit de maquinaria que tenemos, que es un problema financiero, nosotros decimos, primero si nosotros no estamos bien físicamente, emocionalmente, difícilmente 
la máquina anda, entonces tratamos de que nosotros estemos bien y la máquinas también, pero no tiene que fallar la parte humana, es lo que tenemos que atacar más" (trabajador de Chilavert)

La segunda de las dificultades está relacionada con la necesidad de contar con más personal. Y a diferencia de la necesidad de nueva maquinaria, cuestión reductible a términos puramente financieros, esta problemática no lo es. En las ERT el trabajo tiene prioridad sobre el capital y si bien éste se considera necesario, únicamente lo es en su carácter instrumental. Pero son conscientes de que la ganancia salarial es el único criterio que tiene valor para muchos trabajadores y de ahí la dificultad para encontrar personal que asuma dicha prioridad y las responsabilidades derivadas de la autogestión.

"lo que pasa que es muy complicado, en la administración, tomar conciencia, toda la gente que estuvo viviendo el proceso de recuperación que tuvo que dormir seis meses acá es distinto, a aquel que viene a trabajar, se piensa que es un trabajo más, que hay una persona en la oficina que te paga, entonces eso cuesta mucho hacer tomar conciencia de que acá te llevás lo que vos generás, y a mucha gente nosotros le enseñamos con todo el cariño para el futuro de él y se van porque no hay un buen sueldo" (trabajador de Chilavert)

“no es porque no haya gente, y volvemos a lo económico, porque por ejemplo acá un maquinista está ganando 3000 pesos, vamos a suponer, y un maquinista en una empresa privada está ganando 7000 pesos, 8000, 9000 entonces como ha venido uno la última vez hace 6 meses, uhh, qué bueno, ¿cuánto ganan ustedes?, 3000, el tipo no apareció más, es así” (trabajador de Chilavert)

Hay en esta visión una crítica implícita que los trabajadores de Chilavert hacen al comportamiento economicista de otros trabajadores cuya raíz se encuentra en los cambios generados por la autogestión tanto en su concepción de la empresa como del trabajo. La responsabilidad individual de cada trabajador, derivada ahora de la apropiación del trabajo transforma la implicación y participación constante en la gestión de la empresa a través de la horizontalidad de las relaciones, el aprendizaje y el descubrimiento de habilidades generados en las prácticas cotidianas que devienen valores frente a la ganancia salarial como único objetivo.

"el problema es que los compañeros entiendan que hay buenos tiempos y malos tiempos, ese es el problema, porque cuando baja el trabajo, al no producir, el retiro va a ser menor, los compañeros tienen que entender eso, que no por culpa del tesorero, el presidente o el secretario pierde trabajo es porque... la economía lo hace así" (trabajador de Chilavert)

En este sentido se hace explícita la diferencia que se establece en los discursos recogidos entre la lógica dominante en las empresas capitalistas y la política 
empresarial de los trabajadores. Frente a las relaciones laborales de jerarquía y subordinación que caracterizan a la empresa privada, la igualdad y la horizontalidad son los criterios que determinan la participación de cada trabajador en las empresas recuperadas, respecto a los cuales la ganancia salarial pierde primacía.

En cuanto a las fortalezas, la coincidencia discursiva se pone de manifiesto alrededor de la noción de ser un grupo que ha compartido esfuerzos y objetivos. La voluntad de seguir enfrentando los obstáculos para mantener el trabajo y la capacidad de lucha por defenderlo representa para los trabajadores de Chilavert la principal fortaleza y recurso con el que cuentan. Las palabras que resultan ser claves en su discurso son, unión, compañerismo y compromiso respecto a la resolución de problemas.

\footnotetext{
"para mí lo positivo es que somos pocos, todos tiramos para el mismo lado y está abierta la cuerda para quien venga, eso es lo mejor que tenemos" (trabajador de Chilavert)

"el desafío de los compañeros, el empuje que hay para llevarlo adelante esto y después la experiencia que hacemos, quizá la amistad que formamos con otros grupos, otros compañeros, otros estudiantes, siempre te mandan una palabra de aliento, no estamos solos" (trabajador de Chilavert)

"el recurso más importante es el trabajo, si hay que quedarse te quedás, si hay que venir un sábado, vienes" (trabajador de Chilavert)
}

También cabe destacar la mención que hacen a los apoyos con los que han contado y la difusión que han tenido como ERT dada la apertura que practican con otras instituciones como la UBA en la promoción de la investigación y el conocimiento sobre los procesos de recuperación.

"yo creo que tuvo una difusión tan grande que siempre tenemos mucha ayuda, incluso nos fortalece económicamente la cuestión de tener tanta difusión, aparte de apoyo" (trabajador de Chilavert)

Por último hay que mencionar la significación que alcanza para los trabajadores la introducción de criterios de democratización y de solidaridad. En cuanto a la democratización de la empresa, los trabajadores de Chilavert establecieron procesos asamblearios de toma de decisiones cuyos anclajes se encuentran referenciados a la experiencia de lucha y conflicto de los trabajadores. Chilavert se incluye en el $44 \%$ de las ERT que realizan una asamblea semanal aunque de manera cotidiana debatan sobre cualquier cuestión de la empresa. Acerca del carácter asambleario de las ERT es necesario tener en cuenta que está más bien ligado a la inclusión de significaciones y prácticas de igualdad, horizontalidad y participación real de todos los trabajadores que a la normativa cooperativista (Ruggeri, 2009). En el 73\% de las ERT en las que se trabaja el mismo número de horas se establece un reparto igualitario de los salarios, contemplando diferencias en función de criterios a respetar como la antigüedad (PFA, 2010). 
Respecto a las prácticas de solidaridad hay que mencionar por un lado, apoyos a nuevas recuperaciones brindando información, ayuda o seguimiento de protestas organizadas. Por otro, la inclusión de actividades solidarias con las que abrir la empresa al entorno barrial para fines sociales habilitando para ello espacios dentro de la empresa. Chilavert engrosa el $57 \%$ de ERT que realizan algún tipo de actividad solidaria (PFA, 2010). Dentro de las instalaciones del taller se realizan diversas actividades sociales y culturales. En la política que denominan de "fábrica abierta", los trabajadores ceden espacios para la realización de este tipo de actividades como una forma de agradecimiento a la comunidad vecinal por el apoyo prestado y también como una manera de contribuir a la articulación de lazos e intercambios que trascienden la lógica productiva del trabajo.

Bajo el nombre de "Chilavert recupera" se crea un centro cultural en el que se organizan talleres, cursos y exposiciones de teatro, danza, fotografía, etc. También se ha creado un sistema de pasantías con diversas escuelas para estudiantes de secundaria y una escuela de secundaria cuya homologación ha sido reconocida por el gobierno de la CABA (Ciudad Autónoma de Buenos Aires) en el que dan clases estudiantes y graduados del Instituto Superior del Profesorado Joaquín V. González y de la CEIP (Cooperativa de Educadores e Investigadores Populares) quienes hasta el 2011 no habían recibido ninguna remuneración económica.

Hay que mencionar igualmente el Centro de Documentación de ERT creado a través de un convenio con la Facultad de Filosofía y Letras de la UBA. En este centro se recopila y archiva información diversa sobre ERT a nivel nacional incluyendo bibliografía, entrevistas realizadas por distintos investigadores que han pasado por allí y también información estadística a través de los Tres Relevamientos realizados hasta ahora por el proyecto de investigación Programa Facultad Abierta (PFA, 2003, 2004, 2010).

La relación entre Chilavert y el Centro de Documentación es de colaboración e intercambio. Para los trabajadores y para el equipo de investigación, según ambos cuentan, resulta un enriquecimiento mutuo de conocimiento e información. Para los trabajadores es de gran ayuda y satisfacción colaborar en la creación de un archivo en el que se pueda consultar la información recopilada sobre las ERT, su situación y problemáticas. Para los investigadores supone la posibilidad de que la universidad cumpla un papel activo en la colaboración resolutiva de las dificultades del proceso de recuperación.

Algunos autores han señalado este tipo de actividades como aspectos de innovación y creatividad característicos de las ERT (Trinchero, 2007, Ruggeri, 2009). Para los trabajadores estas actividades tienen una gran importancia como elemento de diferenciación y particularidad de las ERT respecto al modelo anterior de empresa que han vivido.

"las actividades sociales son una forma de abrir la empresa a la comunidad, al barrio, como agradecimiento por el apoyo recibido" (trabajador de Chilavert) 
"hay empresas recuperadas que no son como la nuestra, las recuperan para trabajar, no socialmente, nosotros sentimos que las recuperamos para la sociedad, aparte del trabajo, claro, el centro cultural, el bachillerato, le damos un lugar a la gente del teatro, del centro de documentación" (trabajador de Chilavert)

Es una forma de poner en práctica una concepción de la empresa y del trabajo que trasciende el carácter exclusivamente productivo y que pone de manifiesto la compatibilidad entre su concepción de la empresa y del trabajo con prácticas de solidaridad en el entorno social que les rodea, siendo el del barrio el más inmediato. La introducción de criterios de democratización y solidaridad representa para los trabajadores una manera de desarrollar una gestión distinta a la dominante en el marco del actual capitalismo flexible en el que los trabajadores sufren las consecuencias de políticas orientadas por intereses economicistas y particulares. La visión compartida alrededor de la importancia que alcanzan estas prácticas explicita la significación política de los procesos de recuperación como proyecto autogestinarios.

\section{La visión de futuro}

La visión que los trabajadores tienen sobre el futuro muestra distintas vertientes. Aunque se muestran conscientes de la influencia que tienen factores que escapan a su control en el actual marco global comparten una voluntad clara de continuar. Las motivaciones principales señalan la satisfacción personal ante la recuperación que han llevado a cabo y la defensa de puesto de trabajo ante lo que consideran un ataque injusto que no generaron.

"sí bueno, para mí el sentimiento es que ya llevamos imprimiendo ocho años ... (risas) no es poco, no es poco, hemos hecho buenas, malas cosas, hemos dado tumbos pero son ocho años que llevamos adelante, y esto tiene que seguir" (trabajador de Chilavert)

Con la defensa del trabajo consideran haber defendido su identidad y dignidad como trabajadores frente al comportamiento fraudulento que mantuvo el antiguo dueño de la empresa que en aquellos momentos no se trataba de un caso aislado en el país. En este sentido, el carácter político que adquiere la lucha colectiva por mantener el trabajo y tratar de sortear todos los obstáculos nutre las distintas visiones de los trabajadores de Chilavert en torno a la acción colectiva que coprotagonizan juntos como principal referencia que articula la visión de futuro.

"yo apunto a que sea un futuro mejor, que nos lleve a demostrar que somos capaces, que no todo lo que habíamos dicho y pensado era una locura, un grupo fuerte, con convicciones firmes de seguir trabajando, no sé si triunfará económicamente pero en lo que es humanamente vamos a estar allí, bienvenido el futuro" (trabajador de Chilavert) 
“el futuro yo lo veo bien, y si no anda la cooperativa no sólo es un fracaso para mí y para los compañeros, ... no sé cuánto más puedo llegar a tener heridas pero voy a cumplir en pocos meses 50 años, qué voy a conseguir, ser otro desocupado, buscando que me paguen en negro, ... o voy a hacer piquetes para seguir viviendo, es como que si la cooperativa va mal yo ando mal, me entra el bajón... mientras yo vea que puedo apoyarlos, los voy a apoyar hasta lo último, hubo meses buenos, años buenos, otros que no... también" (trabajador de Chilavert)

De ahí que se muestren optimistas en cuanto a la continuidad de Chilavert en lo que dependa de sus esfuerzos y esté en sus manos. Hay poco espacio en su visión y en sus discursos para nociones irrealmente estables mientras que lo que consideran realmente importante es no cambiar la consistencia fundamental de lo que es una ERT.

“¿el futuro?.. confuso (risas) depende de muchas cosas que no se controlan... existen varias posibilidades, primero esto puede crecer ... aunque lo que más miedo nos da, lo peor que puede pasar es que nos autotransformemos en otra cosa..... empezamos a explotar gente, a vivir del trabajo ajeno, (risas) o sea volver a la rueda de... es la peor de todas las opciones, la derrota se completa, no?,...si no podemos hacer libros, haríamos puertas no sé, (risas), y la otra opción es salir fortalecidos, que podamos crecer, el balance es bastante positivo, es de cero a algo, no teníamos nada, así que sí ha sido positivo" (trabajador de Chilavert)

\section{Conclusiones}

Teniendo en cuenta que las ERT son cooperativas autogestionadas por los trabajadores que después de ser declaradas en quiebra o abandonadas tras el fracaso de la gestión empresarial y el incumplimiento de las relaciones contractuales son puestas en funcionamiento de nuevo por éstos, su particularidad en calidad de respuesta colectiva recae sobre el término recuperación. En las condiciones descritas, devolver la empresa a la producción y seguir trabajando como objetivo pone de manifiesto el carácter defensivo de las lógicas de acción colectiva desarrolladas.

La recuperación de Chilavert se produce en el año 2002. Su contextualización como caso particular se ubica en el momento de mayor expansión del proceso, coincidente con la crisis por la que atraviesa el país en el 2001. Aunque es necesario tener presente los antecedentes con los que cuentan las ERT, ya desde la década de los años 50, los cuales las enmarcan en las luchas protagonizadas a lo largo de la historia por las clases populares.

Escasamente representativas desde un punto de vista cuantitativo, su relevancia radica en la sostenibilidad que han supuesto ser para más de nueve mil quinientos puestos de trabajo en un contexto de desempleo y precarización continuos. Se trata de una respuesta generada por la necesidad y que se desarrolla y resuelve de manera 
particular en cada uno de los casos ya que la discrecionalidad de los jueces y la no aplicación de las leyes aprobadas en Argentina sobre ERT no permiten hablar de una implicación estatal real.

De ahí el interés en centrar este trabajo en la significación subjetiva que tiene el proceso para los trabajadores que protagonizaron la recuperación de Chilavert. La consideración del protagonismo agencial de los trabajadores en el estudio de las ERT permite concretar conceptualmente la experiencia como un proceso de respuesta colectiva que tiene por objetivo mantener el puesto de trabajo frente al cierre empresarial.

La visión de los trabajadores sobre su propia respuesta es la de una defensa colectiva del trabajo en una situación sin opciones. La necesidad de no perder el trabajo ni las importantes deudas salariales son las razones principales para iniciar el proceso de recuperación. A partir de ahí conciben su acción como una defensa del trabajo que se hace sinónimo de su identidad y dignidad como trabajadores frente a los comportamientos fraudulentos que encarnaba mayoritariamente el sector empresarial en medio de la inacción generalizada de representantes políticos $\mathrm{y}$, en un primer momento, también de representantes sindicales. Frente a esos actores, otros como la familia, los vecinos y organizaciones de ERT les dieron su apoyo dotando así de legitimidad social su acción.

Aunque hoy continúan enfrentando problemas y dificultades, principalmente económicas y de personal, los ocho años transcurridos ponen de manifiesto la sostenibilidad de su autogestión. En una resolución constante de asuntos cotidianos tienen además la satisfacción de haber seguido trabajando durante estos años y de haber conseguido así su objetivo.

Y es alrededor de este objetivo donde se articula el carácter político de su lucha, inseparable en la visión de los trabajadores de su condición colectiva. Algo que se expresa en la consideración de ser y saberse un grupo que comparte esfuerzos alrededor del objetivo común de trabajar como una de sus principales fortalezas. Esta visión vertebra la narración discursiva en un planteamiento de futuro en el que sólo cabe enfrentar las dificultades y contrariedades que se presenten.

La satisfacción ante el éxito de la autogestión es una referencia semántica que comparten y que aparece estrechamente ligada no sólo a la recuperación empresarial en términos productivos sino en la medida que ha implicado la democratización de las relaciones laborales y la participación en actividades solidarias.

Conscientes de la existencia de múltiples factores que escapan a su control en el actual marco de flexibilidad laboral comparten, no obstante, la importancia que tiene diferenciar estos factores de aquellos que, por el contrario, dependen de ellos. En éstos se centra hoy la continuidad de su respuesta de lucha colectiva por resolver definitivamente la situación legal y seguir manteniendo el trabajo. 


\section{Bibliografía}

Alonso Benito, L.E. (2000). Trabajo y posmodernidad: el empleo débil. Madrid: Fundamentos.

Castells Oliván, M. (2005). La era de la información: economía, sociedad y cultura. Vol. I La sociedad red. Madrid: Alianza Editorial.

Castillo Alonso, J.J. (2003). En la jungla de lo social: reflexiones y oficio de sociólogo. Madrid: Miño y Dávila.

Carnoy, M. (2001). El trabajo flexible en la era de la información. Madrid: Alianza Editorial.

De Sousa Santos, B. (2006). La Sociología de las Ausencias y la Sociología de las Emergencias: para una ecología de saberes. En publicación: Renovar la teoría crítica y reinventar la emancipación social (encuentros en Buenos Aires). Disponible en la World Wide Web: http://bibliotecavirtual.clacso.org.ar/ar/libros/edicion/santos/Capitulo\%20I.pdf (www.clacso.org)

Fajn, G. (comp.) (2003). Fábricas y Empresas Recuperadas. Protesta social, autogestión y rupturas en la subjetividad. Buenos Aires: Ediciones del Instituto Movilizador de Fondos Cooperativos.

Fernández Alvárez, M. I (2004). Continuidades y rupturas en el proceso de trabajo. Una mirada antropológica a partir de una experiencia de ocupación/recuperación de fábricas durante el año 2002. Intersecciones en Antropología. Núm. 5, 141-151.

Greenwood, D.J. (2000). De la observación a la investigación - acción participativa: una visión crítica de las prácticas antropológicas. Revista de antropología social. Núm. 9, 27 - 49.

Magnani, E. (2003). El cambio silencioso. Empresas y fábricas recuperadas por los trabajadores en la Argentina. Buenos Aires: Prometeo.

Perelman, L. (2002). Patrones de participación en el mercado aboral de los trabajadores del Gran Buenos Aires. Serie Documentos de trabajo Núm. 141, Equipo Técnico Mutidisciplinario, Santiago de Chile: OIT.

Prieto Rodríguez, C. (2002). La degradación del empleo o la normal social del empleo flexibilizado. Sistema: Revista de ciencias sociales. Núm. 168 -169, 89-106. 
Programa Facultad Abierta (PFA) (2003). Informe del Relevamiento de ERT. Facultad de Filosofía y Letras UBA En www.recuperadasdoc.com.ar.

Programa Facultad Abierta (PFA) (2004). Informe del Segundo Relevamiento de ERT.Facultad de Filosofía y Letras UBA En www.recuperadasdoc.com.ar.

Programa Facultad Abierta (PFA) (2010). Informe del Tercer Relevamiento de ERT. Facultad de Filosofía y Letras UBA En www.recuperadasdoc.com.ar.

Rebón, J. (2004). Desobedeciendo al desempleo. La experiencia de las empresas recuperadas. Buenos Aires: Ed. La Rosa Blindada / PICASO.

Rebón, J. (2006). Las empresas recuperadas por sus trabajadores en Argentina. Cuadernos de relaciones laborales. Vol. 24, Núm. 2, 149 - 17.

Ruggeri, A. (2004). La política en las Empresas recuperadas. Ponencia al II Congreso Nacional de Sociología.

Ruggeri, A.; Martínez, C. y Trinchero, H. (2005). Las empresas recuperadas en la Argentina. Informe del segundo relevamiento entre empresas recuperadas por sus trabajadores. Buenos Aires: Facultad de Filosofía y Letras. Universidad de Buenos Aires.

Ruggeri, A. (Comp.) (2009). Las empresas recuperadas. Autogestión obrera en Argentina y América Latina. Buenos Aires: Ed. De la Facultad de Filosofía y Letras.

Sennett, R. (2000). La corrosión del carácter: las consecuencias personales del trabajo en el nuevo capitalismo. Barcelona: Anagrama.

Stiglitz, J. (2006). Cómo hacer que funcione la globalización. Madrid: Taurus

Trinchero, H. (2007). Economía política de la exclusión. Para una crítica desde la experiencia de las empresas recuperadas por sus trabajadores (ERT). Cuadernos de Antropología Social. Núm. 26, $41-67$. 